\title{
LOGIT MODEL AND PREDICTION QUALITY OF CONTINUOUSLY CAST SLABS
}

\author{
'Zdeněk FRANĚK, ${ }^{2}$ René PYSZKO \\ ${ }^{1}$ Silesian University in Opava, School of Business Administration, Karvina, Czech Republic, EU, \\ franek@opf.slu.cz \\ ${ }^{2}$ VŠB - Technical University, Faculty of Materials Science and Technology, Ostrava, Czech Republic, EU, \\ rene.pyszko@vsb.cz
}

https://doi.org/10.37904/metal.2020.3642

\begin{abstract}
In the paper there are summarized basic analytical and empirical pieces of knowledge on searching dependences of the influence of thermal process during steel casting in the continuous casting of semi-finished products - slabs, on their quality assessment and as well the influence of thermal processes on the quality of final products rolled of slabs. The course of thermal processes at continuous steel casting has the significant impact on the quality of slabs. The assessment of the quality of slabs during continuous steel casting is an inseparable part of the information system of a metallurgical plant. This assessment works on the data collection and storing the necessary data for an effective assessment between measured and qualitative quantities. The paper describes the proposal of the concept of quality slab prediction. There are statistical methods used for this purpose, especially association rules and logistic regression. On the basis of use of the system for monitoring the casting parameters and the application of statistical methods, association rules for prediction of quality of continuously cast slabs were determined.
\end{abstract}

Keywords: Metallurgy, continuous casting of steel, slab, association rules, logistic regression

\section{INTRODUCTION}

Thermal processes in a slab taking place during its passing through the complete facility of the continuous steel casting (hereinafter referred to as "CSC" only) present a complex multi component thermal, thermodynamic, hydrodynamic and thermo-mechanical system. The knowledge about it and the solution require an interdisciplinary approach which is impossible without the use of monitoring system [1] of casting parameters and various mathematical models $[2,10]$. From the off-line version to the on-line version, where the entry data, taken directly from specific CSC, serve for the calculation and imagining of the slab thermal field at any moment and any place in the course of passing through the casting machine. Today, the technical level of these models is, thanks to the modern hardware, at the development stage allowing the calculation and the presentation of results of the thermal processes to be in line with the real process in the given CSC. An example of such a thermal model, working in real time, is the thermal model developed at VŠB TU Ostrava [3] and VUT Brno [4]. Within research of the thermal slab field, during the solidification and the development of the software solution of the thermal model of slab solidification and cooling, there has been the theory of the solution described in detail. When setting up the numerical model of the not stationary thermal slab field, we had to settle the difficult definition of surrounding conditions. It was described, for the sake of simplicity, by the Fourier-Kirchhoff equation. In the programming way, the thermal numerical model was set up with the utilization of the network method (final differences) [5].

When we resolve complex thermal processes taking place in the cast slab, we have to start with their characteristic parameters, which must be clearly defined and given into connection with the quality parameters of the cast slabs and, then even sheets rolled out of these slabs. They are measurable parameters with the 
possibility of numerical or graphical imagining of their trends. Basically, they are all measured temperatures, including the temperature of cooling media, the flow values, cooling media pressures as well as the values of a number of thermal quantities calculated on-line by the thermal model. It is also possible to list the factors having the effect vicariously on the thermal processes. They are specifically the casting speed, which influences the shape and the length of the liquid slab core, the diagonal slab movements and its deformation, bulging, the fluctuation of the chemical steel and casting powder compositions, the fluctuation of the steel level in the mould, the crystallographer oscillation, etc. However, in addition to these parameters, there are also other non-measurable CSC parameters existing, which influence the slab quality. For example, we can talk about the steel flow in the solidifying slab at the interface of a liquid phase - mushy zone and mushy zone and the solid phase.

The objective of the research works has been the establishment of the quality dependency on technological casting values. It means the dependency when the prescribed value of a specific parameter is breached and a specific kind of defect occurs in the slab. We have to say that when analysing the dependencies of the quality parameters on indicators of thermal processes, there are only few clear, simple and direct results. It means finding "just one nonstandard indicator the slab defect". Frequently, there is a complex of reasons leading to non-quality faulty slab production.

Another objective was to establish the dependency of occurrence of defects in the rolled sheets on specific defects in the slab.

When we resolved the mentioned issue, we utilized statistical methods in the course of data processing of the annual CSC production. We tipped off the most important parameters and determined limits of exceeding or not reaching of which should indicate the relevant defect kind. This gave us a set of simple association rules, i.e., if the determined parameter limit is breached, then a defect occurs. This is a common principle in the prediction systems [6]. Similarly, there were dependencies of the slab defect determined, then the defect in the sheet. These rules were established especially on the basis of experience of CSC technologists. The utilization of data and the statistical methods was just the supporting means.

There are modern methods of artificial intelligence, based on gained knowledge from data (the so-called data mining) serving in the prediction of specific defect kinds, according to the complex of breached parameters. It is the method of the logistic regression [7] and the method of neuron nets [8], fuzzy neuron nets [9] respectively.

\section{SET UP OF ASSOCIATION PRODUCTION RULES}

The assessment of the slab quality in facilities of continuous steel casting makes a part of the information system in the metallurgical plant. This system usually works with all data accessible from CSC processes. The parts of the system are the data recording and filtration, their classification, saving in the relational database system, the data aggregation and their graphic interpretation. Thus, the precondition for the data filtration is created, while the necessary data aggregation serves the statistical processing. The aggregation is necessary for simplification of the works and for the handling a huge number of data. It shows that the data aggregation from one meter of the cast slab is purposeful enough and satisfactory. There was a matrix of independent variables prepared for the data processing - of the technological parameters and dependable variables - the slab defects. Within the research, we selected steel parameters, parameters of the casting and of the casting machine, which relate to the temperature losses in the slab in CSC. They can have their effects on the quality of cast slabs characterized by the shape of their macrostructures, but especially by the occurrence or lack of defects.

In the course of the research, we progressively utilized the following basic statistical methods for the melt assessment and analysis and the sequence: the descriptive statistics of measured values, frequency histograms, data filtration and cleaning, correlation analysis, linear regression, quadratic regression, classification tables, and the association rules. 
With the use of the above-mentioned statistical methods, 20 parameters were tipped off for which association prediction rules were set up. For the review and parameter, examples with the set up limits for the controls workers see Table 1.

Table 1 The set up of the prediction values for the controls by workers

\begin{tabular}{|c|l|l|l|l|l|l|l|}
\hline No. & Parameter & Limitations & Tech. Unit & No. & Parameter & Limitations & Tech. Unit \\
\hline 1 & Aluminium loss ladle & Upper limit & $\%$ & 15 & Abnormal. Steel level & Event & - \\
\hline 2 & Aluminium loss tundish & Upper limit & $\%$ & 16 & Handling on steel level & Event & - \\
\hline 3 & Cast speed by sulphur & Upper limit & $\%$ & 17 & Max. dif. Temp. Mould N & Upper limit & ${ }^{0} \mathrm{C}$ \\
\hline 4 & Cast speed by tundish & Upper limit & $\%$ & 18 & Min. dif. Temp Mould N & Upper limit & ${ }^{0} \mathrm{C}$ \\
\hline 5 & Abs. speed limit (min) & Lower limit & $\mathrm{m} / \mathrm{min}$ & 19 & Max. dif. Temp. Mould BF & Upper limit & ${ }^{0} \mathrm{C}$ \\
\hline 6 & Abs. speed limit (max) & Upper limit & $\mathrm{m} / \mathrm{min}$ & 20 & Min. dif. Temp Mould BF & Upper limit & ${ }^{0} \mathrm{C}$ \\
\hline 7 & Speed ramping & Upper limit & $\mathrm{m} / \mathrm{min}^{2}$ & 21 & Mould oscilattion & Deviation & $\%$ \\
\hline 8 & Stand still & Upper limit & $\mathrm{sec}$ & 22 & Spray water flow 1 & Deviation & $\%$ \\
\hline 9 & Steel level tundish & Lower limit & $\mathrm{kg}$ & $23-35$ & Spray water flow $2-13$ & Deviation & $\%$ \\
\hline 10 & Vortex effect tundish & Upper limit & $\mathrm{V} / \mathrm{min}$ & 36 & Ladle inert gas presure & Deviation & $\%$ \\
\hline 11 & Lancing - oxygen use & Event & - & 37 & Ladle inert gas flow & Deviation & $\%$ \\
\hline 12 & Submerged nozzle posit. & Deviation & $\mathrm{mm}$ & 38 & TundishMould gas Press & Deviation & $\%$ \\
\hline 13 & Mold level & Deviation & $\mathrm{mm}$ & 39 & TundishMould gasFlow & Deviation & $\%$ \\
\hline 14 & Casting powder & Event & - & 40 & Signal ML-tektor & Event & - \\
\hline
\end{tabular}

These rules were then interpreted for the information system. For each parameter it is possible to display a graph with limits. For example see Figure 1.

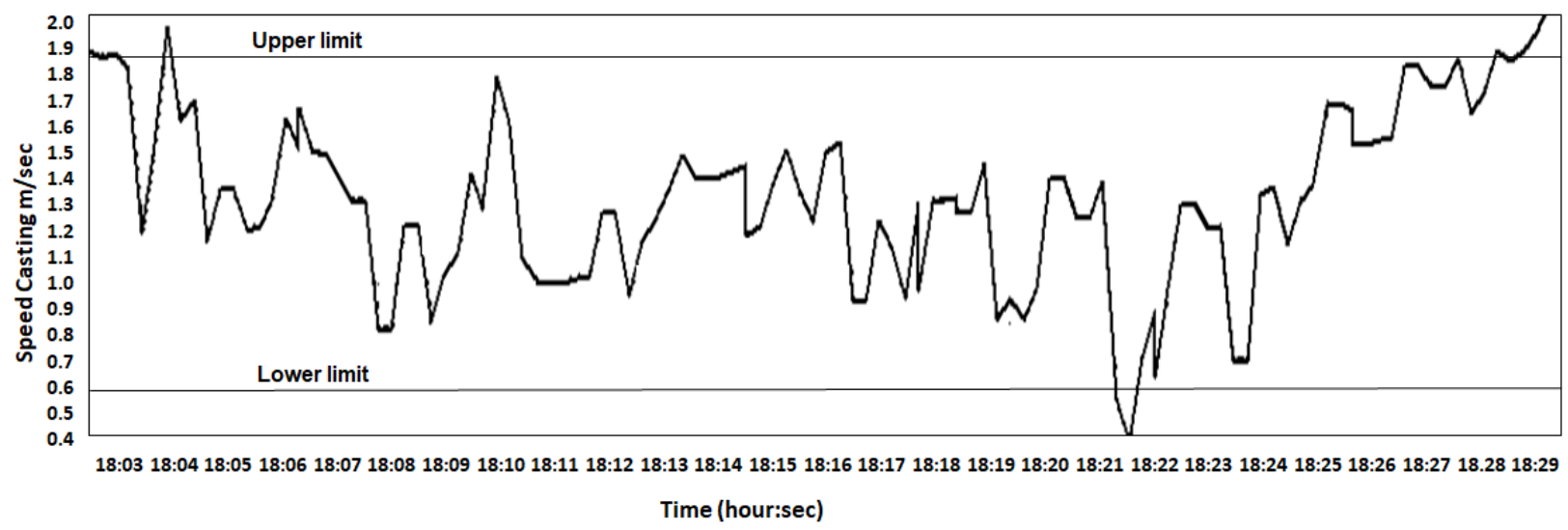

Figure 1 Graphic interpretation of the casting parameters and the prediction rules

\section{THE PREDICTION WITH THE AID OF THE LOGIT MODEL}

Within the research works, the logistic regression was tested. The principle is the setup of a formula based on data predicting a defect with some probability: for the phenomenon prediction - that a certain selected defect in the material would occur, the statistical method of the logistic regression was used. The principle of this method7 was based on the estimated values of the regressive coefficients in the logistic regression model having the following form

$$
\begin{aligned}
& \mathrm{P}(V)=\frac{1}{1+e^{-Z}} \\
& Z=b_{0}+b_{1} X_{1}+b_{2} X_{2}+\ldots+b_{n} X_{n}
\end{aligned}
$$


Where $P(V)$ is the defect probability $V(1)$,
bj - regression coefficients, $j=0,1,2, \ldots, n$,
$X_{j} \quad-\quad$ predictors - the independent variables (features), $\mathrm{j}=1,2, \ldots, \mathrm{n}$,
n $\quad$ - $\quad$ the number of predictors (1).

Unlike the method of the smallest squares, which is used for the estimation of the middle value of regression coefficients in the linear regression model, the method of the maximal trustworthiness is used for the estimation of regression coefficients in the logistic regression model. It provides the most probable values of the regression coefficients. The logistic regression model is the non-linear model and thus the statistical software SPSS7 was used, where the method of the logistic regression at the disposal is suitable for solving the prediction of defects in materials.

The interpretation of the results of the logistic regression is illustrated in the following example of the simplest logistic model with single (dichotomist) regressors. For better illustration, imagine that the repressors $\mathrm{x}$ means the existence of the defect risk. The explained variable $Y$ means the presence of the defect sign. The frequency of the observed situations could be entered into the table with four fields, see Table 2.

Table 2 Table with the four fields

\begin{tabular}{|c|c|c|c|}
\hline Risk/Defect & $X=1$ & $X=0$ & Sum \\
\hline$Y=1$ & a & b & a + b \\
\hline$Y=0$ & c & d & c + d \\
\hline Sum & a + c & b $+d$ & $n$ \\
\hline
\end{tabular}

The association ratio of normal values (the odds ratio) is calculated by the formula $O R=(a \times d) /(b \times c)$.

The ability of the above-described method of the logistic regression to predict defects in slabs was tested on an extensive set of real production data. The example used the real but adjusted and statistically treated production data from the total of 8601 slabs produced in the period of about half a year. Each slab was assigned with the numerical average values of twenty predictors marked X1, X2, ., X20, in the model (1), (2) $\mathrm{n}=20$. The values of predictors present the values measured in the slab during the production process (their overview is in Table 3).

Table 3 Overview of predictors

\begin{tabular}{|c|c|}
\hline $\mathrm{X} 1$. Steel overheating $\left({ }^{\circ} \mathrm{C}\right)$ & X11. Heat flux, MR $\left(W \cdot m^{-2}\right)$ \\
\hline X2. Casting speed $\left(\mathrm{m} \cdot \mathrm{min}^{-1}\right)$ & $\mathrm{X} 12$. Heat flux, VR $\left(\mathrm{W} \cdot \mathrm{m}^{-2}\right)$ \\
\hline X3. Acceleration $\left(\mathrm{m} \cdot \mathrm{min}^{-2}\right)$ & X13. Oscillation KR $\left(\mathrm{min}^{-1}\right)$ \\
\hline X4. Weight in the tundish $(\mathrm{Kg})$ & X14. Water flow in the secondary cooling, zone $\mathrm{Z1}\left(\mathrm{I} \cdot \mathrm{min}^{-1}\right)$ \\
\hline X5. $\Delta \mathrm{t}$ in the mould, $\mathrm{PB}\left({ }^{\circ} \mathrm{C}\right)$ & X15. Water flow in the secondary cooling, zone Z1s $\left(I \cdot \mathrm{min}^{-1}\right)$ \\
\hline X6. $\Delta t$ in the mould, $\mathrm{PB}\left({ }^{\circ} \mathrm{C}\right)$ & X16. Water flow in the secondary cooling, zone $Z 2\left(I \cdot \mathrm{min}^{-1}\right)$ \\
\hline $\mathrm{X} 7 . \Delta \mathrm{t}$ in the mould, $\mathrm{MR}\left({ }^{\circ} \mathrm{C}\right)$ & X17. Water flow in the secondary cooling, zone Z3 $\left(I \cdot \mathrm{min}^{-1}\right)$ \\
\hline $\mathrm{X} 8 . \Delta \mathrm{t}$ in the mould, $\mathrm{VR}\left({ }^{\circ} \mathrm{C}\right)$ & X18. Water flow in the secondary cooling, zone Z4i $\left(I \cdot \mathrm{min}^{-1}\right)$ \\
\hline X9. Heat flux, PB $\left(W \cdot m^{-2}\right)$ & X19. Water flow in the secondary cooling, zone Z4a $\left(I \cdot \mathrm{min}^{-1}\right)$ \\
\hline $\mathrm{X} 10$. Heat flux, LB $\left(\mathrm{W} \cdot \mathrm{m}^{-2}\right)$ & X20. Water flow in the secondary cooling, zone Z5 $\left(I \cdot \mathrm{min}^{-1}\right)$ \\
\hline
\end{tabular}

Apart from that, for each slab, if the monitored defect $\mathrm{V}$ (cracks) occurred and that is expressed with the values 1 or $0(1=$ defect has occurred, $0=$ the defect had not occurred $)$. 
The output from the SPSS software, where the values of all regression coefficients assigned to the relevant predictors, including the level constant, i.e., the regression coefficient b0, give us the statistically important coefficients (on the basis of the Wald's test): X1, X3, X7, X11, X14, X15, X16, X18, and X20.

The entering the predictor values for a specific slab into (1) and then to (2) gives us defect occurrence $V$ probability $p$ for the product. Comparison of the probability $p$ with the decision-making line $p=0.5$ we decide on the prediction value. If we repeat this process for all 8601 semi-products, we get all predicted values which we compare with the actual occurrence of the monitored defect $\mathrm{V}$.

In the relevant prediction model (1), (2) the formula (2) has got the form

$$
\begin{aligned}
& Z=-8.664-0.049 \cdot X_{1}-1.914 \cdot X_{3}-2.118 \cdot X_{7}+11.384 \cdot X_{11}-0.017 \cdot X_{14}+ \\
& +0.030 \cdot X_{15}+0.003 \cdot X_{16}+0.004 \cdot X_{20}
\end{aligned}
$$

The classification ability of the model coming out of the software SPSS is in Table 4.

Table 4 The output from the SPSS software: Classification table for the decision-making (cut) limit 0.5 .

\begin{tabular}{|l|r|r|r|l|}
\hline & & Predicted & & \\
\hline & & $V$ & & $\%$ correct \\
\hline Observed & & 0 & 1 & \\
\hline$V$ & 0 & $\mathbf{3 8 7 1}$ & $\mathbf{1 2 6 4}$ & $75.4 \%$ \\
\hline Overall Percentage & 1 & $\mathbf{1 4 9 5}$ & $\mathbf{1 9 7 1}$ & $56.9 \%$ \\
\hline
\end{tabular}

This way of identifying the logistic regression model is called, in the SPSS software, the "Enter Method". The classification table clearly suggests that the prediction characteristics of the model are not ideal. While the model predicts correctly in the situation of no defect occurrence $-75.4 \%$ products, there are $56.9 \%$ slabs predicted correctly when the defect occurs.

The above-presented example clearly shows that the method of association rules and the logistic regression is useful for the considered issue of the prediction of defect presence in materials. In order to use the method on the specific issue of predicting the defect presence in produced slabs, we would need more in depth going analysis of the logistic regression model with the focus on other metallurgical characteristics of the continuous slab casting process, their possible mutual relations

\section{CONCLUSION}

The results of statistical analyses and the graphic presentation of the parameters in the course of casting, together with the assessment of slabs and sheets' quality, were utilized for the operating assessment and the production management. CSC workers have the chance to look for trends of individual deviations by sequence and to see differences compared with the previous sequences. The system allows for the monitoring of more than 100 values. There are association rules in the form of prediction limits set in the system. These are monitored by the workers of the quality management.

The results of the process analysing the course of melts are reflected in the set up limits, the so-called limit values. Their exceeding or not achieving indicates the breaches in the optimal course of casting. The workers in the department of the organization and the technical management utilize, for this purpose, a screen in the form of a table in the information system of the steelworks. These tables are created by the steel qualities. When the set limits are exceeded, the workers inspect the slabs or reassign them for other orders, see Table 1 
and Figure 1. The exceeding of the set limits was marked by the highlight background. The slab inspection uses also visual control of the slab surface, or after the control firing.

\section{ACKNOWLEDGEMENTS}

This paper was supported by the Ministry of Education, Youth and Sports Czech Republic within the Institutional Support for Long-term Development of a Research Organization in 2020, SP2020/34 "Low energy systems and materials in industrial technologies"

\section{REFERENCES}

[1] FRANEK Z., KAVICKA F., STETINA J. Software Analytical Instrument for Assessment of the Process of Casting Slabs, In 10th International Conference on Numerical Methods in Industrial, Forming Processes NUMIFORM. Pohang, Republic of Korea, 2010, pp. 586-592. doi:10.1063/1.3457607.

[2] MAUDER T., STETINA J. High Quality Steel Casting by Using Advanced Mathematical Methods. METALS. 2019, vol. 8, iss. 12 , no. 1019 . DOI: 10.3390/met8121019.

[3] VELICKA M., DITTEL D., PYSZKO R. Research of Thermal Processes for the Continuous Casting of Steel, Materiali in Tehnologije. 2013, vol. 47, no 6, pp. 815-818. Available from: http://mit.imt.si/Revija/izvodi/mit136/velicka.pdf.

[4] STETINA J., KLIMES J., MAUDER T. Control of Soft Reduction of Continuous Slab Casting with a Thermal Mode. Materiali in Tehnologije. 2015, vol. 49, no 5, pp. 725-729. doi:10.17222/mit.2014.189.

[5] LALLY B., BIEGLER L., HENEIN H. Finite Difference Heat-Transfer Modelling for Continuous Casting. MTB. 1990, vol. 21, no. 4, pp. 761-770. doi:10.1007/BF02654255.

[6] FOGUEM B. K., RIGAL F., MAUGET F. Mining Association Rules for the Quality Improvement of the Production Process. Expert Systems with Applications. 2013, vol. 40, pp. 1034-1045. doi:10.1016/j.eswa.2012.08.039.

[7] HOSMER D. W., LEMESHOW S. STURDIVANT R.X. Applied Logistic Regression. New York: John Wiley \& Sons, 2013.

[8] ZHANG G., PATUWO B.E., HU M.Y. Forecasting with Artificial Neural Networks: The State Of the Art. International Journal of Forecasting. 1998, vol. 14, no. 1, pp. 35-62. doi:10.1016/S0169-2070(97)00044-7.

[9] CHIN-TENG L. Support-Vector-Based Fuzzy Neural Networks. International Journal of Computational Intelligence Research. 2005, vol. 1, no. 2, pp. 138-150. http://ctlin.nctu.edu.tw/BioSOC/publication/1012.pdf.

[10] MAUDER T., STETINA J., KLIMES L. Quality Improvement of Continuously Cast Special Steel by Using Numerical-Optimization Model, In METAL 2017: 26th International Conference on Metallurgy and Materials. Ostrava: TANGER, 2017, pp. 52-58. 